\title{
8
}
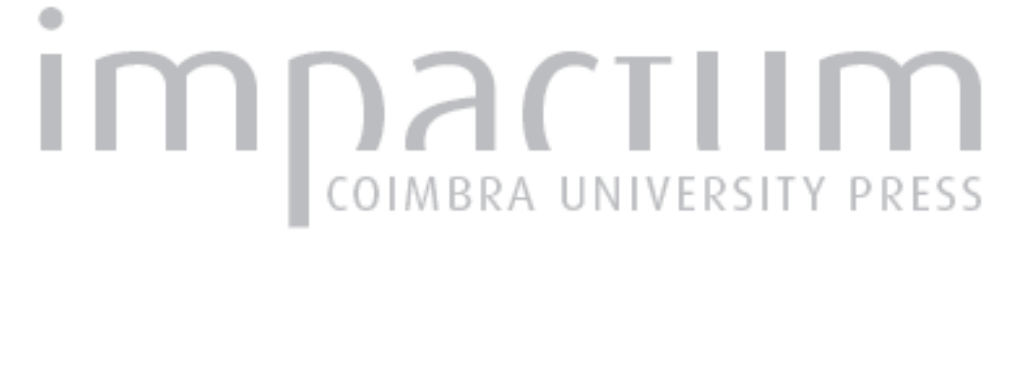

\section{A cadeira de História da Educação na FLUC (1930-1974)}

\section{Autor(es): $\quad$ Marques, Maria Alegria}
Publicado por: Faculdade de Letras da Universidade de Coimbra, Instituto de História Económica e Social

URL persistente:

URI:http://hdl.handle.net/10316.2/28009

DOI:

DOI:http://dx.doi.org/10.14195/0870-4147_42_16

Accessed : $\quad$ 26-Apr-2023 04:24:46

A navegação consulta e descarregamento dos títulos inseridos nas Bibliotecas Digitais UC Digitalis, UC Pombalina e UC Impactum, pressupõem a aceitação plena e sem reservas dos Termos e Condições de Uso destas Bibliotecas Digitais, disponíveis em https://digitalis.uc.pt/pt-pt/termos.

Conforme exposto nos referidos Termos e Condições de Uso, o descarregamento de títulos de acesso restrito requer uma licença válida de autorização devendo o utilizador aceder ao(s) documento(s) a partir de um endereço de IP da instituição detentora da supramencionada licença.

Ao utilizador é apenas permitido o descarregamento para uso pessoal, pelo que o emprego do(s) título(s) descarregado(s) para outro fim, designadamente comercial, carece de autorização do respetivo autor ou editor da obra.

Na medida em que todas as obras da UC Digitalis se encontram protegidas pelo Código do Direito de Autor e Direitos Conexos e demais legislação aplicável, toda a cópia, parcial ou total, deste documento, nos casos em que é legalmente admitida, deverá conter ou fazer-se acompanhar por este aviso.

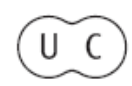





\title{
A cadeira de História da Educação na FLUC $(1930-1974)^{*}$
}

\author{
Maria Alegria Marques \\ Faculdade de Letras da Universidade de Coimbra \\ Centro de História da Sociedade e da Cultura - FLUC \\ mfm@fl.uc.pt
}

Resumo:

Surgido a propósito do centenário da Faculdade de Letras da Universidade de Coimbra, este trabalho pretende traçar as linhas de evolução da cadeira de História da Educação, de 1930 a 1974, através dos seus docentes e dos programas que ministraram.

Palavras chave:

História da Educação; História da Faculdade de Letras; Programas curriculares; Formação de professores.
Abstract:

Produced in the context of the Faculty of Arts of the University of Coimbra first centenary, this article tries to outline the evolution of the discipline of History of Education, from 1930 to 1974 , considering the professors who were in charge of it and their respective syllabi.

Keywords:

History of Education; History of the Faculty of Arts; Syllabi; Teacher training.

* Com algumas ligeiras alterações, este texto é o mesmo que serviu de base à comunicação que apresentámos ao VIII Congresso Luso - Brasileiro de História da Educação. Infância e Relações de Género na História da Educação, na Universidade Federal do Maranhão, São Luís do Maranhão, Brasil, de 22 a 25 de Agosto 2010, em colaboração com o nosso Colega Doutor Fernando Maia, da Faculdade de Ciências do Desporto e Educação Física da Universidade de Coimbra, a quem deixamos o reconhecimento da nossa gratidão pelo auxílio prestado na investigação. A sugestão do tema prendeu-se com o centenário da Faculdade de Letras da Universidade de Coimbra, a ocorrer em 2011. 


\section{Introdução}

Há um século - Outubro de 1910 -, iniciava-se em Portugal uma nova fase da sua história. Em tempos de aspiração a mudanças, a vitória da revolução republicana que então se viveu, era, em tudo, um "renascer do mundo", como o dia primeiro capaz de trazer a materialização da esperança e a alegria num novo e promissor devir.

Esbatidos os fumos da vitória, sobrevinda a dura realidade do dia-a-dia, de um país exaurido e de um povo analfabeto, o campo que se abria à República era imenso, onde toda a obra era necessária ou possível. Assim na educação. Os números que se aventam não deixam lugar a dúvidas: Portugal era um país de analfabetos ${ }^{1}$. E se assim era na instrução primária, não podiam ser muito risonhas a educação secundária, nem, muito menos, a superior ${ }^{2}$.

Qualquer alteração ao estado da educação pressupunha mestres capazes de levar a bom porto os desideratos das políticas suas orientadoras. Essa existência, por sua vez, exigia organismos ou entidades não já e apenas certificadoras desses agentes, mas também responsáveis pela sua formação. Também, neste campo, o novo regime político percebeu as necessidades com que se confrontava e tentou dar-lhes resposta, pelo menos nos níveis que estavam mais imediatamente ao seu alcance, o ensino primário e o ensino secundário ${ }^{3}$.

A proposta de solução do problema da falta de agentes credenciados para o ensino não superior, particularmente o secundário (pois é com esse que se liga o problema que pretendemos tratar) ${ }^{4}$ veio, em 1911, pela criação das Escolas

1 1910: 74\%; 1911: 69,6\% (apud A. H. de Oliveira Marques, "Escolas e Ensino", in Nova História de Portugal. Direcção de Joel Serrão e A. H. de Oliveira Marques. Vol. XI. Portugal da Monarquia para a República. Lisboa, Presença, 1991, p. 519). Além de que conviria conformar as gerações mais jovens segundo o novo ideário. Para tal, nada melhor que a escola, que os novos corifeus da Nação queriam também laica.

2 Ver A. H. de Oliveira Marques, ob. cit. p. 519-576. Como leitura orientadora acerca do estado da nação portuguesa neste período de transição de regime, pode ver-se também Rui Ramos, A segunda fundação (1890-1926). História de Portugal, direcção de José Mattoso. VI. Lisboa, Círculo de Leitores, 1994, p. 17-37.

3 A este propósito, Oliveira Marques escreve mesmo: "Encarando, no seu conjunto, a política de ensino e o desenvolvimento da instrução ao longo dos trinta primeiros anos do século XX, é possível concluir pela preocupação acentuada que os mesmos regimes políticos lhe foram tributando. Essa preocupação atingiu o seu auge com a proclamação da República e com a grande reforma de 1911, verdadeiro marco miliário da história pedagógica de Portugal" (ob.cit., p. 575).

4 Não se quer com isto significar que antes não houvesse preocupações com o problema, nem que não se tentassem soluções, ainda que, no imediato, fosse a mera continuação do existente, logo rejuvenescida por obra republicana. Vejam-se os antecedentes desta obra republicana em Joaquim Ferreira Gomes, "O Curso de habilitação para o Magistério Secundário", in Para a 
Normais Superiores de Lisboa e Coimbra, anexas às Faculdades de Letras e Ciências das respectivas Universidades ${ }^{5}$. Cometiam-se-lhes várias missões, que se traduziam, na prática, nos objectivos que se pretendiam pela criação, nelas, de três cursos: um para a habilitação ao magistério liceal, um segundo, para o magistério normal primário e um terceiro para o magistério normal superior; no seu conjunto, facultariam ainda a admissão ao concurso para a carreira da inspecção do ensino. Diga-se, contudo, que a formação proposta a ser desenvolvida para tais graus implicava uma relação estreita com outras escolas, mormente pertencentes ao grau de ensino a que se destinava a respectiva formação, nas quais se processaria a prática pedagógica própria a cada um dos graus em referência ${ }^{6}$.

Os cursos, com duração de dois anos, iniciaram-se em 1915-1916, mas a sua existência foi atribulada, quer por algum desentendimento entre as duas entidades que concorriam na formação ${ }^{7}$, quer por algumas desconexões entre os docentes do ano de iniciação na prática pedagógica ${ }^{8}$ e os das metodologias especiais ${ }^{9}$, os quais, por sua vez, dispersos pelos vários liceus e desintegrados da restante formação, trabalhavam em ambiente mais de autodidactismo que de conexão e reciprocidade. O panorama era agravado por algum desfasamento entre as actividades de cada uma das entidades formadoras, com as Escolas Normais Superiores a marcarem o ritmo, em dessintonia com as demais intervenientes na formação, Universidades e liceus.

Tudo isto, em claro agravamento ao longo da década de 20, levou a que os responsáveis pelas reformas da Ditadura, no sector da educação, lhes tentassem apontar uma solução. Havia de chegar pela criação de uma nova Secção nas

História da educação em Portugal. Porto, Porto Editora, 1995, p. 109-115. Tem ainda interesse, do mesmo autor, "A formação pedagógica dos professores do Ensino Liceal durante a Primeira República”, in Novos Estudos de História da Educação. Coimbra, Quarteto Editora, 2001, p. 211-227.

5 Decreto de 21 de Maio de 1911. Sobre a Escola Normal Superior de Coimbra, ver Joaquim Ferreira Gomes, A Escola Normal Superior da Universidade de Coimbra (1911-1930). Lisboa: Instituto de Inovação Educacional, 1989. Ver ainda, do mesmo autor, "As Escolas Normais Superiores", in ob. cit., p. 116-121. Ver ainda, do mesmo autor, A Universidade de Coimbra durante a Primeira República (1910-1926), Lisboa, Instituto de Inovação Educacional, 1990.

6 Ibidem, art. 6. . : “A iniciação na prática pedagógica consta de duas partes:” (...) "2. . Prática pedagógica dirigida, em cada disciplina, pelos respectivos professores de metodologia especial e exercida nas aulas do liceu, da escola normal primária ou da escola primária superior, regidas por esses mesmos professores".

7 Preâmbulo ao Decreto n. ${ }^{\circ}$ 18:973, de 16 de Outubro de 1930.

8 Este ano era, afinal, o primeiro do curso na Escola Normal Superior.

9 Referentes a cada uma das disciplinas do Grupo liceal correspondente ao bacharelato do candidato ao magistério. 
Faculdades de Letras, a Secção Pedagógica (1930). Tal Secção representava o coroar de um sistema, naquilo que dizia respeito à formação docente, ou o seu fecho, se esta fosse entendida como o último elo que havia de ligar uma organização de base do sistema de ensino ${ }^{10} \mathrm{com}$ a sua cúpula, a entidade de formação dos seus próprios agentes.

\section{A criação das Secções Pedagógicas das Faculdades de Letras}

A criação das Secções Pedagógicas das Faculdades de Letras teve lugar pelo Decreto n. ${ }^{\circ} 18$ 937, de 28 de Outubro de $1930^{11}$. Note-se que, à época, apenas existiam Faculdades de Letras nas Universidades de Lisboa e de Coimbra, extinta que fora a experiência efémera na Universidade do Porto.

A leitura do preâmbulo do diploma legal ora citado deixa perceber as intenções e os princípios orientadores da criação. Naquelas, imperava o desejo imediato de aperfeiçoamento do sistema de ensino, com uma proposta de formação de pessoal docente adaptada ao edifício construído ${ }^{12}$ e um outro, mais remoto e mais ambicioso de que este início fosse a raiz de futuras novas escolas, "verdadeiras Faculdades de sciências da educação".

Quanto aos princípios orientadores da fundação, confirmava-se a "divisão entre a cultura pedagógica e a prática pedagógica”, endossando-se cada uma às suas raízes matriciais ou " a quem de direito deve pertencer", segundo a letra da lei, e que eram as Universidades (para a primeira) e as "escolas do grau a que o futuro professor se destina" (para a segunda).

A formação propriamente dita merecia algumas considerações, ao legislador. Assim, ficava expressa a consciência da redução do número de cadeiras, mas também a da sua assertividade. E, sobre a prática pedagógica, desde logo ficava determinado que ela se prolongaria durante dois anos; incidiria sobre todas as disciplinas que o futuro professor poderia ser chamado a reger, e alargar-se-ia a outras funções, nomeadamente às de direcção. Ao mesmo tempo, ficava adscrita a escolas especiais, capazes de "proporcionar aos futuros professores ambientes de trabalho apropriados". Na circunstância, criavam-se "em Lisboa e em Coimbra escolas de preparação prática dos professores de ensino secundário - os liceus normais", dos quais, o de Lisboa, começaria

${ }^{10}$ De recordar que, entretanto, o governo republicano já se ocupara da reforma dos ensinos primário, técnico-profissional e secundário (liceal).

${ }^{11}$ Joaquim Ferreira Gomes, "O Curso de Ciências Pedagógicas e o estágio", in ob. cit., p. $122-125$.

${ }^{12}$ Cfr. supra, nota 7. 
"a funcionar imediatamente pela conversão do Liceu de Pedro Nunes, da mesma cidade". Ademais, ao Liceu Normal de Lisboa cometiam-se funções acrescidas, fazendo dele, em simultâneo, "um meio de aperfeiçoamento de toda a organização e da melhor execução dos serviços do ensino liceal, visto que será, simultaneamente, escola prática do magistério e de aperfeiçoamento profissional, e, (...) centro de ensaios pedagógicos"13.

Do que acabamos de enunciar, interessa-nos, hoje, a parte da cultura pedagógica, aquela cujo conjunto constituía o objecto das Secções Pedagógicas das Faculdades de Letras. Mormente, importa-nos o que foi esta secção, melhor, uma das suas cadeiras na Faculdade de Letras da Universidade de Coimbra, como veremos de seguida.

A referida "cultura pedagógica", constituindo, no seu conjunto, a 3. 'Secção das citadas Faculdades, havia de alcançar-se (ou de aprofundar-se) através da frequência das cadeiras de Pedagogia e Didáctica; História da Educação, organização e administração escolares; Psicologia Geral; Psicologia Escolar e Medidas Mentais; Higiene Escolar. À excepção desta última, que era semestral, todas as outras eram anuais.

Pelo que nos foi dado perceber da leitura das actas dos Conselhos da Faculdade de Letras da Universidade de Coimbra, não causou qualquer espanto ou perturbação este novo dispositivo legal. A Faculdade de Letras da Universidade de Coimbra aceitou a reforma sem qualquer comentário, de satisfação ou contragosto ${ }^{14}$.

${ }^{13}$ Em Coimbra, ficaria em acção o Liceu Júlio Henriques, que havia sido criado pelo Decreto n. ${ }^{\circ} 15971$, de 21 de Setembro de 1928 (depois Normal de D. João III, hoje, Escola Secundária de José Falcão); sobre o liceu de Coimbra, ver Maria Judite de Carvalho Ribeiro Seabra, Os liceus de Coimbra na sociedade coimbrã (1840-1930). Lisboa, [s.n.], 1999.

${ }^{14}$ Sessão extraordinária de 25 de Novembro de 1930; in Manuel Augusto Rodrigues, A Universidade de Coimbra no Século XX. Actas da Faculdade de Letras. II (1925-1936). Coimbra, Arquivo da Universidade de Coimbra, 1991, p. 148. Apenas se acha uma referência à publicação do Decreto que criava a secção pedagógica das Faculdades de Letras e, por consequência, o Director [Professor Doutor Eugénio de Castro] "afirma o seu propósito de se esforçar por conseguir para a Faculdade não só a Biblioteca mas todas as instalações que eram da extinta E.N.S.”. Que assim não seria, pelo menos no que ao espaço da biblioteca dizia respeito, prova-o a acta da sessão ordinária de 2 de Dezembro de 1932, pela qual se percebe que a biblioteca continuava no mesmo lugar, "uma parte do antigo edifício de S. Pedro", de difícil acesso aos professores e alunos da Faculdade de Letras (ibidem, p. 190). Entretanto a 3 de Março de 1931, e suscitado por uma observação do Dr. Oliveira Guimarães, acerca da necessidade da dotação de meios para a biblioteca, para a manutenção das "assinaturas das revistas da especialidade e se adquirirem novos livros", o Conselho decidira "oficiar para as instâncias superiores, pedindo que se transfira para a biblioteca da Faculdade de Letras a dotação da biblioteca da antiga Escola Normal Superior" (ibidem, p. 152). 


\section{A cadeira de História da Educação, organização e administração escolares na FLUC (1930-1974)}

Ao termos sido incumbida de leccionar esta unidade curricular nos últimos três anos, no âmbito do, agora, $2 .^{\circ}$ ciclo de Formação de Professores, e tendo, nós própria, em tempo, frequentado a cadeira de História da Educação, exactamente no âmbito do Curso de Ciências Pedagógicas, há muito que nos questionávamos acerca do seu passado. Aliás, esta dúvida tinha crescido quando, um $\operatorname{dia}^{15}$, descobrimos que, em tempo, ela tinha sido leccionada pelo Prof. Joaquim de Carvalho, um dos nomes ilustres de docentes da mesma Faculdade.

Ora, acontecendo o VIII Congresso Luso-Brasileiro de História da Educação, entendemos por bem considerar a documentação existente acerca da cadeira de História da Educação, durante a vigência do Curso de Ciências Pedagógicas, isto é, entre 1930-1974 ${ }^{16}$.

Assim sendo, a fonte principal do nosso estudo é constituída pelos livros de sumários da cadeira, hoje depositados no Arquivo da Universidade de Coimbra. Aí se encontra a série completa, à excepção do ano de $1940-1941^{17}$, para o qual não se acha qualquer livro de sumários.

Os livros apresentavam já, por então, o formato com que sempre os conhecemos, e com o qual acabaram os seus dias, substituídos que foram, em 2007, por realidades informáticas, através da Página WOC da Universidade de Coimbra.

O tipo de informação que se pode retirar desses materiais cinge-se ao número de lições anuais, ao docente ou docentes responsáveis pela cadeira e à matéria

${ }^{15}$ Éramos, então, Presidente do Conselho Directivo da FLUC. Em resposta à solicitação do Magnífico Reitor, Prof. Doutor Fernando Rebelo, de fazer enviar, ao Arquivo da Universidade de Coimbra, todos os materiais, nomeadamente, livros de sumários, que não tivessem já uma vida útil na instituição, decidiu-se fazer uma selecção, em que se incluíram os livros de sumários até 1975 , bem como currículos académicos de docentes já falecidos, estrangeiros, ou há muito retirados da instituição e da vida académica. Embora o principal trabalho se tenha ficado a dever à Vice-Presidente Prof. Doutora Ana Paula Arnaut, nós própria percorremos tal documentação, percebendo-nos, então, da riqueza que ela representa.

${ }^{16}$ O termo ad quem provém da "extinção" do referido Curso. Sobre a problemática a que se acha intimamente ligado, a formação de professores, veja-se Joaquim Ferreira Gomes, "O Curso de Ciências Pedagógicas e o estágio", in Para a história da educação em Portugal, p. 122-125, e Bártolo Paiva Campos, "Políticas de Formação de Professores após 25 de Abril de 1974", Biblos. Revista da Faculdade de Letras, LV (1979), p. 549-588.

${ }^{17}$ Isto, considerando apenas a cadeira de História da Educação, pois que as séries de outras cadeiras apresentam mais falhas (nomeadamente, Higiene Escolar, Psicologia Geral, Pedagogia e Didáctica). 
leccionada. Muito raramente há mais informação, nomeadamente acerca de bibliografia indicada e de realização de provas de frequência.

Como fonte suplementar, percorremos as actas do Conselho da Faculdade ${ }^{18}$, onde, aqui ou ali, se acha alguma informação relevante à matéria.

Neste contexto, no nosso trabalho consideraremos os seguintes aspectos: o nome da cadeira, os docentes e o programa da cadeira referente a cada um deles ${ }^{19}$.

\subsection{Nome da cadeira}

Nascida, neste Curso das Secções Pedagógicas das Faculdades de Letras, como História da educação, organização e administração escolares, atendendo aos livros de sumários e crendo que eles reflectem a designação senão oficial, pelo menos a que corria na Escola, inclusive no seu Conselho, foi designada de maneiras muito diversas ao longo dos anos. Assim, logo no primeiro ano (1930-1931) e no primeiro sumário, o docente indicava, como nome da cadeira, História da Pedagogia, que logo emendava para História da Organização Escolar $^{20}$, designação que manteria até 1935-1936, embora, por vezes, com alguma indecisão quanto à nomenclatura a fixar. Isso mesmo se verifica em 1933-1934 e 1935-1936, quando a designação de História da Organização Escolar oscila com a de História da Educação ${ }^{21}$.

Que esta oscilação de nome, reveladora de alguma indefinição relativamente ao objecto de estudo, não era mero lapso do docente, prova-o o registo dos próprios sumários. Assim, em 1931-1932, no primeiro sumário, pode ler-se a seguinte referência "A história da pedagogia: seu conceito, fins e utilidade. Suas relações com a história da civilização e com a história da Filosofia" e,

${ }^{18}$ Manuel Augusto Rodrigues, ob. cit. Percorremos ainda dois volumes manuscritos, os quais contêm as actas das reuniões do Conselho entre 15 de Outubro de 1936 e 13 de Outubro de 1961 e 28 de Outubro de 1961 e 25 de Março de 1974, respectivamente. Agradecemos ao Ex.mo Senhor Director da Faculdade de Letras, Prof. Doutor Carlos André, a facilidade que nos concedeu para a consulta destas fontes.

${ }^{19}$ Sendo que estamos consciente de que com o concurso de outras fontes se poderá ir mais longe, nomeadamente quanto ao número de alunos, classificações e licenciaturas de que eram provenientes.

${ }^{20}$ Escreveu, inicialmente, História da Pedagogia, acabando por riscar a palavra Pedagogia, para a substituir por Organização Escolar.

${ }^{21}$ Em 1933-1934 inicia o registo dos sumários como História da educação, mantém por mais duas lições, regressando a História da Organização Escolar, situação que quase repete no ano seguinte, quando o primeiro registo foi sob o título de História da Educação, para, logo no segundo, regressar a História da Organização Escolar. 
em 1932-1933, igualmente no sumário relativo à abertura do ano lectivo, "Conceito e objecto de estudo. História da pedagogia".

Portanto, neste aspecto, podemos concluir que houve alguma indefinição na fixação do título da cadeira. A designação de História da Educação só veio a verificar-se, sem margem para dúvida e em definitivo, em 1936-1937.

\subsection{Os docentes}

Ao longo dos quarenta e cinco anos da sua vigência, a cadeira de História da Educação foi assegurada por vários docentes da Faculdade de Letras da Universidade de Coimbra, alguns deles nomes grandes da história da cultura portuguesa.

O primeiro responsável da cadeira foi Joaquim de Carvalho, professor da FLUC desde 1916-1917, onde ingressou como 2. ${ }^{\circ}$ assistente provisório, tendo feito uma longa e ilustre carreira, até $1958^{22}$.

A sua presença na docência da cadeira de História da Educação e da Organização Escolar surge naturalmente, pois que ele fora já docente na Escola Normal Superior de Coimbra. Aliás, numa acta do Conselho da Faculdade, de 27 de Fevereiro de 1942, lê-se precisamente esse argumento como justificação de a cadeira lhe ficar atribuída para o ano lectivo seguinte ${ }^{23}$.

Concluiu-se, pois, que Joaquim de Carvalho foi responsável pela leccionação da cadeira de História da Educação e da Organização Escolar ou tão-só de História da Educação durante 28 anos. Pode dizer-se que assumiu sempre esse serviço docente, pois que, ao longo dessas quase três décadas completas, apenas se assinala uma única interrupção, no ano lectivo de 1952-1953, por se ter deslocado ao Brasil, em missão cultural. Seria, então, substituído

${ }^{22}$ Memoria Professorum Universitatis Conimbrigensis. 1772-1937. Direcção de Manuel Augusto Rodrigues. II. Coimbra, Arquivo da Universidade de Coimbra, 1992, p. 70. Para a bibliografia de Joaquim de Carvalho, ver Biblos. Revista da Faculdade de Letras. LVI (1980). Homenagem a Joaquim de Carvalho, p. VII-XIV.

23 "Na Secção de Ciências Pedagógicas, fez-se a seguinte distribuição de serviço:

O Professor Joaquim de Carvalho continua a reger a cadeira de História da Educação, para a qual em tempo foi nomeado quando esta cadeira fazia parte do quadro da extinta Escola Normal Superior.".

Já agora e a propósito, acrescente-se que Joaquim de Carvalho chegou à cadeira de História da Pedagogia, na Escola Normal Superior, em 1920, em substituição do então Director dessa Escola, Dr. Luciano António Pereira da Silva (vide Joaquim Ferreira Gomes, A Escola Normal Superior..., p. 227, n. 4). Veio a obter a nomeação definitiva, na cadeira, em 1923 (vide Joaquim Ferreira Gomes, ob. cit., p. 248). 
pelo Prof. Sílvio Lima ${ }^{24}$, também ele docente da Secção de Filosofia, mas cujos interesses se alargavam à Psicologia, como é reconhecido ${ }^{25}$.

Não admira, pois, que à morte de Joaquim de Carvalho, em 27 de Outubro de 1958, tenha sido ele o escolhido para a continuidade na docência da cadeira de História da Educação.

Veio a reger esta disciplina até ao ano de 1961-1962. Durante estes anos, pôde contar com a colaboração de dois assistentes, José Ferreira da Silva, também ele um homem ligado ao campo da Psicologia, e Joaquim Ferreira Gomes, clérigo, recém-chegado à docência na Faculdade de Letras. A colaboração do primeiro foi verdadeiramente fortuita e passageira, cremos mesmo que ligada a alguma perturbação que a morte de Joaquim de Carvalho provocou na Faculdade, essencialmente no campo da distribuição do serviço docente. Pelo menos, assim interpretamos o facto de ela se ter verificado apenas no ano lectivo de 1958-1959.

Sobrevindo problemas de doença a Sílvio Lima, com a sua passagem ao estatuto de aposentado ${ }^{26}$, haveria de ser Joaquim Ferreira Gomes o verdadeiro continuador da cadeira de História da Educação. Pela primeira vez, a Faculdade

${ }^{24}$ Por decisão do Conselho da Faculdade em reunião ordinária de 31 de Julho de 1952. Que foi uma escolha acertada, provam-no o facto de o mesmo Conselho se ocupar da situação da cadeira, na sessão de 21 de Janeiro de 1953, e os termos em que o fez: "Considerando-se que o número de alunos que, de facto, passaram a assistir às aulas teóricas de História da Educação excede a lotação dos anfiteatros, decidiu-se fazer o respectivo desdobramento em duas turmas, a partir do princípio do próximo mês de Fevereiro".

${ }^{25}$ Sobre o percurso académico de Sílvio Lima, ver José Ferreira da Silva, "Sílvio Lima, história de um professor universitário", Manuel Viegas Abreu, "Relembrando o "Problema da Recognição' de Sílvio Lima, mestre da atitude crítica e do método experimental" e "Bibliografia", Biblos. Revista da Faculdade de Letras. LV. Miscelânea em honra de Sílvio Lima, 1979, p. XXXV-XLII, XLIII-XLVII e XL-LIII, respectivamente; Maria Helena da Rocha Pereira, "Doutor Sílvio Lima (1904-1993)", Biblos. Revista da Faculdade de Letras, LXX (1994), p. 630-631. Para a sua colaboração, na área de Psicologia, no âmbito da Licenciatura em Filosofia e do Curso de Ciências Pedagógicas, ver Memoria Professorum Universitatis Conimbrigensis, II, p. 75. Aí se pode analisar essa colaboração: Psicologia Geral, Psicologia Experimental, Psicologia Escolar, Introdução à Psicologia, Seminário de Psicologia, e, a culminar, o desempenho do cargo de Director do Laboratório de Psicologia Experimental. Para uma visão mais abrangente do pensamento e da obra deste professor, ver Paulo Archer de Carvalho, Sílvio Lima: um místico da razão crítica: da incondicionalidade do amor intellectuallis. Coimbra: [s.n.], 2009. Aí (p. 236), este autor adscreve a Sílvio Lima a participação na docência em História da Educação (1942-1944) e Organização e Administração Escolares (1954-1956), denotando desconhecimento quanto à organização curricular então vigente (não existia qualquer cadeira com o nome de Organização e Administração Escolares), e incorrendo em erro quando indica os anos referidos como aqueles em que Sílvio Lima assumiu a leccionação de História da Educação.

${ }^{26}$ Sê-lo-ia a partir de 01.03.1965; cfr. Memoria Professorum..., II, p. 75. 
de Letras da Universidade de Coimbra tinha um docente que haveria de fazer, da cadeira, o seu campo de investigação e acção. No entanto, também ele havia de ter necessidade de um substituto, em momento especial do seu percurso académico ${ }^{27}$. Então, foi Aura Montenegro Ferrão, também ela ligada à área da Psicologia, quem ocupou o lugar de docente da cadeira de História da Educação. Mas, também ela, de forma passageira e fortuita.

\section{3. $O(s)$ programa $(s)$}

Sendo conhecido que a liberdade de pensamento, logo, a de ensinar, é um dom maior no ensino universitário, não causam estranheza algumas peculiaridades que os sumários da cadeira em apreço apresentam, ao longo dos diferentes tempos da sua existência. As matérias leccionadas, patentes no registo dos sumários, representam as diversas formações dos docentes que regeram a disciplina, bem como os seus gostos intelectuais e também o seu entendimento do fim da cadeira à preparação dos alunos que a frequentavam.

Isto significa também que nos encontramos perante diversos programas ou, talvez melhor, face a variantes de um mesmo programa.

Dos quatro docentes que tiveram a seu cargo a cadeira de História da Educação, deve-se a Joaquim de Carvalho o único programa que nos chegou em letra de forma, diremos mesmo que, mais que isso, ele nos deixou aquilo que se poderá considerar as suas lições de História da Educação ${ }^{28}$.

Quanto aos restantes, relativamente a Joaquim Ferreira Gomes pode esboçar-se o seu programa através da forma como indica as diversas matérias, no próprio livro de sumários, logo em $1962-1963^{29}$. Sobre os demais, tentaremos reconstituí-los, com a certeza de que fica enorme o fosso entre o resultado de tal intenção e as aulas em que tais programas se desenvolveram. A matéria com que estamos a trabalhar é inerte, morta, enquanto as aulas foram o espaço vivo, não só de exposição de ideias, mas também de expressão de dúvidas, de momentos de diálogo, de oportunidade de confronto de ideias.

${ }^{27}$ Segundo o seu curriculum, "De Setembro de 1972 a fins de Junho de 1973 (com interrupção nos meses de Março, Abril e Maio), frequentou, como Bolseiro da Fundação Calouste Gulbenkian, na qualidade de «élève libre», a Faculté de Psychologie et des Sciences de l'Éducation da Universidade de Lovaina" (ver Joaquim Ferreira Gomes, Curriculum vitae, Coimbra, ed. autor, 1973, p. 6. Sobre a sua actividade nos referidos meses, ver ibidem).

28 "[Esboço de uma História da Educação]", in Joaquim de Carvalho, Obra completa. VI. História das instituições e pensamento político. 1930 - c. 1957. Lisboa, Fundação Calouste Gulbenkian, [Braga, 1989], p. 295-519.

${ }^{29}$ Arquivo da Universidade de Coimbra (A.U.C.), Faculdade de Letras, Sumários, cx. 41, n. ${ }^{\circ} 4$. 
Todos os programas desenvolvidos ao longo das quatro décadas e pouco de vigência da cadeira o foram segundo uma perspectiva diacrónica e se centraram nos espaços e realizações culturais da Europa Ocidental. Porém, nem todos apresentam a mesma abrangência temporal, nem deixam perceber a mesma ênfase nas temáticas comuns.

Assim, vejamos as linhas do programa dos diversos docentes, da sua cristalização ou das eventuais alterações que ele pode ter manifestado ao longo do tempo.

Uma vez que foi a figura de Joaquim de Carvalho a que pontificou na docência da cadeira, bem como a ele se deve o único programa publicado, partiremos da sua apresentação e análise para a observação e comentário dos demais.

Eis, pois, o programa leccionado por Joaquim de Carvalho:

\section{PRELIMINARES}

I. Objecto e conceito de História da Educação.

II. Valor subsidiário do estudo da educação nos povos primitivos e nas civilizações orientais.

\section{CAPÍTULO I. A EDUCAÇÃO NA GRÉCIA}

I. O ideal homérico como ponto de partida dos ideais helénicos.

II. A Educação em Esparta.

III. A educação em Atenas.

1. Sentido geral.

2. A educação até ao aparecimento dos Sofistas.

3. Os sofistas. Significação histórico-pedagógica.

4. Sócrates. Fundamentos do Saber e do Bem. O método socrático.

5. Isócrates. Génese da educação retórica.

6. Antístenes e Aristipo. O ideal do sages.

7. Platão. Suas concepções pedagógicas mais características.

8. Aristóteles. Concepções pedagógicas fundamentais.

IV. A educação no período helenístico. Características e significação histórica.

\section{CAPÍTULO II. A EDUCAÇÃO EM ROMA}

I. Preliminares.

II. Teor da originária educação romana (séculos VIII-III a.C.).

III. Inovações educativas de influência helénica (séculos III-I a.C.).

IV. A educação durante o Império.

V. Literatura romana de significação histórico-pedagógica. 


\section{CAPÍTULO III. A EDUCAÇÃO NA ALTA IDADE MÉDIA}

I. As invasões dos bárbaros e a ruína das instituições escolares romanas. Compilações didácticas dos séculos V e VI.

II. A Igreja e as novas bases do ensino.

III. Carlos Magno. A difusão do ensino como elemento de unificação religiosa e política. Alcuíno e Rabão Mauro.

IV. Desenvolvimento do ensino eclesiástico secular.

V. O ensino no século XII. Disciplinas de estudo e método docente.

VI.A instituição da licentia docendi e o alargamento do ensino.

VII. A educação do cavaleiro.

\section{CAPÍTULO IV. O CRISTIANISMO E A CONSTITUIÇÃO DE NOVO IDEAL EDUCATIVO E DE NOVAS INSTITUIÇÕES DOCENTES}

I. Sentido do ideal educativo cristão.

II. Primeiras instituições docentes cristãs.

III. Concepções pedagógicas de Clemente de Alexandria, de São Jerónimo e de Santo Agostinho.

\section{CAPÍTULO V. A EDUCAÇÃO NA BAIXA IDADE MÉDIA}

I. As Universidades. Significado e modalidade das origens.

II. Organização das Universidades medievais.

III. Método de ensino nas Universidades medievais.

IV. As corporações de ofícios e a preparação de artífices. O ensino particular. As escolas municipais.

V. Literatura pedagógica medieval.

\section{CAPÍTULO VI. O HUMANISMO E A EDUCAÇÃO}

I. A Renascença e as novas condições do ensino.

II. O Humanismo e a concepção formativa das línguas clássicas. O método dos colóquios.

III. Educadores e tratadistas italianos de formação humanista.

IV. Difusão do ensino das humanidades nos países ocidentais.

V. Concepções pedagógicas de Rodolfo Agrícola, Erasmo, Luís Vives, Rabelais e Montaigne.

CAPÍTULO VII. A REFORMA PROTESTANTE E O ENSINO. ACTIVIDADES E CONCEPÇÕES PEDAGÓGICAS DE LUTERO, MELANCHTON, TROTZENDORF E JOÃO STURM

CAPÍTULO VIII. A CONTRA-REFORMA EA EDUCAÇÃO. A COMPANHIA DE JESUS E O ENSINO PREPARATÓRIO 
Em bom rigor, o programa, assim apresentado em síntese, encontra-se apenas publicado na Obra Completa. Mas ele tem por fonte uns Apontamentos de História da Educação ${ }^{30}$, por certo aquelas lições do mestre, que Sílvio Lima indicou na bibliografia, em 1952, quando o substituiu, ocasionalmente, e que mais não seriam que aquilo que, durante muito tempo, no meio estudantil coimbrão, foi considerado uma sebenta. De todo o modo, bem poderemos considerar que ele representa a súmula daquilo que Joaquim de Carvalho acabou por considerar o "seu" programa da cadeira de História da Educação.

O responsável pela publicação da Obra Completa e seu prefaciador, José V. de Pina Martins, justifica o título que entendeu por bem oferecer ao longo capítulo em que se espraia o conteúdo por que se desenvolvia a súmula apresentada: "Intitulámo-lo «Esboço», mas trata-se de um «Esboço» per modo di dire: são duzentas e vinte e seis páginas cheias, admiravelmente escritas, porque cristalinamente pensadas, e recheadas não só de uma riquíssima erudição mas de ideias modernas e com uma informação bibliográfica opulenta e actualizadíssima" ${ }^{\prime 1}$.

Confrontando quer a súmula programática, quer o seu desenvolvimento, com os sumários da cadeira, registados por Joaquim de Carvalho, ao longo dos anos, teremos de aceitar a opinião de Pina Martins acerca do «Esboço» programático de História da Educação: “É, julgamos, o canto do cisne do grande educador intelectual. Porque, de facto, ficou incompleto (...)"32. Na verdade, a análise dos sumários mostra o programa de Joaquim de Carvalho cristalizado num tempo que parava no séc. XVII. As concepções de Locke e as congregações religiosas de jansenistas e oratorianos foram, por norma ${ }^{33}$, a sua baliza última ao longo de tantos anos de docência.

Se os sumários espelharem, fielmente, as temáticas explanadas nas aulas, poderemos afirmar que o programa de Joaquim de Carvalho se foi modelando ao longo do tempo, com a consideração de novos temas, pensamento de autores ou realizações de pedagogos. Por exemplo, no que à cultura romana diz respeito, a consideração de alguns pedagogos além de Quintiliano (Séneca e Plutarco)

${ }^{30}$ Ibidem, p. [521].

${ }^{31}$ Ob. cit., p. VIII.

32 Ibidem.

${ }^{33}$ Entendemos desta forma, porque nem sempre os sumários registam esta temática, ficando-se, nesses casos, por tempos anteriores, normalmente a Contra-Reforma. Como é sabido, a extensão ou o cumprimento de um programa no Ensino Superior (pois é apenas este que ora nos importa) depende de muitos factores, mormente o calendário lectivo, o ambiente em que decorre o ano escolar, a chamada do professor a outras actividades, com a sua ausência das aulas. 
só surge sumariada em 1947-1948; relativamente à reforma protestante, enquanto a referência a Melanchton e de Trotzendorf está presente em 19321933, a de J. Sturm somente ficou registada em 1950-1951. Mas não deixa de ser um programa essencialmente voltado para a história das instituições educativas, como bem nota o seu antigo discípulo, Joaquim Ferreira Gomes, que acrescenta a nota de que o Mestre fazia incidir "particular relevo" no estudo da Universidade ${ }^{34}$.

Por sua vez, Sílvio Lima mostra um programa com outras características. Assumindo a cadeira como substituto, Sílvio Lima desenvolveu um programa que, não se afastando das linhas trilhadas pelo professor da cadeira, as prolongava, bem como, e talvez mais importante, introduzia alguma lufada de ar fresco nas interpretações que propunha, bem como aduzia elementos da sua formação e da sua propensão para os estudos psicológicos.

Assim, em 1952-1953, o programa acima apresentado, relativo a Joaquim de Carvalho, foi prolongado até Rousseau e à projecção educativa das suas ideias em Pestalozzi e em Fröebel ${ }^{35}$. Saldava-se, assim, por alguma inovação, aqui ligada à especialização do docente na área da Psicologia.

Mas a novidade não se ficava por este aspecto. As interpretações do docente, que se percebem bem dentro das novidades da interpretação histórica do momento e bem próximas de problemáticas culturais da época ${ }^{36}$, atrairiam, sem dúvida, os alunos ${ }^{37}$.

Sílvio Lima voltaria à regência da cadeira em 1958-1959, na sequência da morte de Joaquim de Carvalho e regeria a cadeira até 1962, ano já bem próximo da sua aposentação (1965). É de notar que o desenvolvimento do seu programa não mais alcançaria o âmbito temporal que apresentou em 1952-1953 ${ }^{38}$.

Durante esta sua segunda fase na docência da cadeira, Sílvio Lima pôde contar com o concurso de pessoal auxiliar. Referimo-nos ao Dr. J. Ferreira da Silva e ao P. Dr. Joaquim Ferreira Gomes, ambos assistentes do Grupo

${ }^{34}$ Situação actual da História da Educação em Portugal. Separata de Revista Portuguesa de Pedagogia (1988), p. 8.

${ }^{35}$ A.U.C., Faculdade de Letras, Sumários, cx. 28, n. ${ }^{\circ} 46$.

${ }^{36}$ Como exemplos, citemos temas como: "A historicidade do homem e o pluralismo das educações"; "Os sistemas educativos, função da estrutura das sociedades"; "Necessidade da história e da sociologia para a compreensão da génese e evolução dos sistemas educativos"; "As relações entre a escola e a sociedade"; "A estrutura escravagista das sociedades gregas".

${ }^{37}$ Cfr. supra, nota 24.

${ }^{38}$ Em 1958-1959 chegou até aos reformadores protestantes; em 1959-1960 ao Renascimento; em 1960-1961, à Contra-Reforma; em 1961-1962 aos jansenistas e oratorianos. Ver A.U.C., Faculdade de Letras, Sumários, cx. $34,{ }^{\circ}{ }^{\circ} 70$; cx. 36, n. ${ }^{\circ} 37$; cx. 37, n. ${ }^{\circ} 50$ e cx. 39, n. ${ }^{\circ} 53$, respectivamente. 
de Filosofia. Ambos foram incumbidos da leccionação das aulas práticas da cadeira, ocupando-se, o primeiro, no ano de $1958-1959^{39}$, e o segundo nos de 1960-1961 e 1961-1962.

Esclarecendo-se que estas aulas eram em número bem menor que as ditas aulas teóricas, uma apreciação do programa desenvolvido por Ferreira da Silva conduz-nos, quase em exclusivo, apenas ao horizonte da civilização grega, com a leitura e comentário de textos de Tirteu e Plutarco ${ }^{40}$. Além dela, passava às concepções de Rousseau, expressas em passos do Émile. Isto é, estas preferências, sobretudo a última ${ }^{41}$, denotam o campo da Psicologia, no qual o docente já se ocupava, por então.

Por sua vez, Joaquim Ferreira Gomes fez a sua estreia na docência da cadeira de História da Educação numa aula prática de 24 de Fevereiro de 1961, tendo leccionado o mesmo tipo de aulas ainda no ano seguinte. Situando-se no domínio da História, explicitou temas tão diversos como "a douta ignorância" e a "maiêutica" socrática, e, em perspectiva diacrónica, a educação das raparigas [em Esparta, Atenas, Roma, no tempo de S. Jerónimo, no tempo de Carlos Magno, no Renascimento e no séc. XVII] ${ }^{42}$.

Seria em 1962-1963 que a cadeira de História da Educação receberia novo impulso na Faculdade de Letras da Universidade de Coimbra. Joaquim Ferreira Gomes era, então, o docente responsável pela cadeira. Os sumários deste ano permitem reconstituir o programa que se propôs desenvolver ${ }^{43}$. Porém, verifica-se que, ao longo dos anos que leccionou a cadeira - e esta foi a sua cadeira na Universidade ${ }^{44}$-, o docente foi enriquecendo o seu programa. Deste modo, poderemos apresentar o seguinte, como o programa de J. Ferreira Gomes ${ }^{45}$ :

${ }^{39}$ A.U.C., Faculdade de Letras, Sumários, cx. 35, n. ${ }^{\circ} 6$.

${ }^{40}$ Excertos das vidas de Licurgo e Sólon.

${ }^{41}$ Podem acrescentar-se-lhe as considerações com que abre o primeiro sumário: "Definição sociológica de educação - educação consciente e pressão inconsciente (acção difusa do meio)".

${ }^{42}$ A.U.C., Faculdade de Letras, Sumários, cx. 37, n. ${ }^{\circ}$ 50; cx. 39, n. ${ }^{\circ} 53$.

${ }^{43}$ A.U.C., Faculdade de Letras, Sumários, cx. 41, n. ${ }^{\circ} 49$.

${ }^{44}$ Ele próprio o confessa no Prefácio à sua obra Novos Estudos de História da Educação, Coimbra: Quarteto Editora, 2001: "Durante cerca de quarenta anos, servi a Universidade de Coimbra na docência, na investigação e na gestão. Das muitas disciplinas que então regi, a que mais me agradou e em cujo domínio fiz investigação cujos resultados resistiram ao tempo foi a História da Educação".

${ }^{45}$ Sob sua orientação, a cadeira teve também a sua sebenta. As sebentas eram apontamentos organizados por um aluno, a partir das notas que apontava nas aulas do docente e que, nalguns casos, este revia, no final. Eram policopiadas, ficando, assim, ao alcance dos alunos. Sendo do conhecimento de todos, a sua existência era oficiosa. Se nos ativermos a este instrumento de trabalho, o programa de J. Ferreira Gomes englobava ainda os problemas da educação na Rússia (período ante-revolução: sécs. XVIII e XIX (políticas de Alexandre I e Catarina II; Tolstoi e a 
Introdução:

I. Conceito de educação: "educere" e "educare".

II. Pedagogia e Educação.

III.Educação e Sociedade.

IV. Objecto da História da Educação: instituições escolares, métodos ou processos de ensino, ideias pedagógicas.

V. Método a seguir (sincrónico).

VI.Os povos primitivos e as civilizações orientais.

A Educação na Grécia

A. O ideal homérico como ponto de partida dos ideais helénicos - noção de "Kalokagathia" e de "areté".

B. A Educação em Esparta: fontes; a constituição de Licurgo; classes sociais: espartanos; periecos e hilotas; Educação para o Estado e pelo Estado; o "paidónomo"; ciclos educativos; a educação das raparigas.

C. A Educação em Atenas: o "milagre grego"; o sentido da "democracia" ateniense.

- Os três períodos da história da educação em Atenas: 1. Até ao aparecimento da "paideia". Os sofronistas; palestras e ginásios; efebia; o pedagogo; o gramatista; o citarista; o pedotriba; a educação feminina. 2. Dos Sofistas a Alexandre Magno. Os Sofistas: noção e significado histórico; Sócrates: significado histórico-pedagógico: a douta ignorância; o método socrático: ironia e maiêutica. Isócrates: o ideal do orador. Platão: significado filosófico e pedagógico; a Academia; o "mundo sensível" e o "mundo das ideias"; teoria das ideias; os vários ciclos de estudo. Aristóteles: significado filosófico e pedagógico; o Liceu; a obra de Aristóteles: obras de significado e interesse pedagógico; o método genético; o objectivo da educação: a formação de bons hábitos e a felicidade; períodos da educação. 3. A educação no período helenístico: educação enciclopédica; três graus de ensino: elementar, médio, superior (o Museu).

A Educação em Roma

Generalidades.

A educação em Roma: características gerais do povo romano; educatio e paideia; educatio e institutio.

Os três períodos da educação em Roma: 1. A educação na Roma antiga; a missão da mãe e a do "pater familias"; o objectivo da educação neste período. 2. A influência helénica na educação romana; condições

escola de Yasnaia Poliana; a Revolução, o Partido Comunista e a educação; os planos quinquenais e a educação; pedagogos russos: Blonsky, Makarenko). No entanto, não lhe encontrámos qualquer referência nos sumários. 
gerais; três graus de ensino: as escolas do litterator, do gramatista e do rhetor; o estudo da filosofia; a música; os ginásios. 3. A educação durante o Império: características gerais; o interesse dos imperadores pelo ensino; a organização do ensino.

O Cristianismo - novo ideal educativo.

Novo conceito de Deus: uno, transcendental, pessoal; novo conceito de homem: o sentido da personalidade humana.

Helenismo e Cristianismo: gnosticismo; corrente "africana" (Tertuliano); corrente grega ou alexandrina.

Primeiras instituições docentes cristãs: os catecumenatos; as escolas catequéticas; as escolas monásticas. O monaquismo: eremitas e cenobitas. S. Bento de Núrcia: a escola interior e a escola exterior. Concepções pedagógicas de alguns Padres da Igreja: S. Clemente de Alexandria, S. Jerónimo, Santo Agostinho.

A educação na Alta Idade Média

As invasões bárbaras e a ruína das instituições escolares romanas. Compilações didácticas dos séculos VI e VII.

A Igreja e as novas bases do ensino: escolas monásticas, escolas catedrais, escolas paroquiais.

S. Martinho de Dume, Santo Isidoro de Sevilha, Beda o Venerável.

Carlos Magno: a difusão do ensino como elemento de unificação religiosa e política. A "escola do palácio”. Alcuíno e Rabão Mauro.

O desenvolvimento do ensino eclesiástico secular: França, Inglaterra, Itália, Espanha, Portugal.

As colegiadas e as congregações de cónegos regrantes: Guimarães e Santa Cruz de Coimbra.

O ensino no século XII: disciplinas de estudo e método docente.

A instituição da licentia docendi: determinação do papa Alexandre III A educação do cavaleiro.

As Universidades medievais

As universidades como corporação: "universitas magistrorum et scholarum"; modalidades das origens: a) "ex consuetudine"; b) "ex privilegio"; c) "ex seccessione"; o "jus ubique docendi"; a autonomia da universidade; universidades de tipo magistral e universidades de tipo estudantil; a liberdade intelectual; universidades e "studium generale". A organização das universidades: a) o estudo das "artes" e as "faculdades"; b) as "nações", os procuradores, os reitores, os decanos, os funcionários; c) os graus escolares; d) a vida material dos estudantes; os hospícios e os colégios; a literatura goliárdica; o método 
escolástico: a "lectio" e a "disputatio". A Universidade portuguesa: a acção da Igreja e do rei; a confirmação do Papa.

As corporações de ofícios e a preparação de artífices. O ensino particular. As escolas municipais.

Literatura pedagógica medieval: Rabão Mauro, Hugo de S. Vítor, Abelardo, Vicente de Beauvais, S. Tomás, João Gerson.

Tempos modernos

A. Alguns acontecimentos:

1. Renascença e Humanismo; 2. Protestantismo; 3. Reforma católica; nascimento das principais nações modernas; descobertas geográficas; invenções modernas: bússola, pólvora, imprensa.

B. Novo meio educativo

1. A religião; 2. O Estado; 3. A vida social; 4. A família.

C. A organização do ensino

1. O ensino primário; 2. O ensino secundário; 3. O ensino superior.

A. Pedagogos humanistas

a) Vitorino da Feltre: a Casa Giocosa; b) Desidério Erasmo; c) João Luís Vives; d) Francisco Rabelais; e) Michel Montaigne; f) Literatura para a educação de príncipes e nobres até ao séc. XVIII.

B. Pedagogos protestantes

a) A Reforma e o ensino; b) Martinho Lutero; c) Filipe Melanchton, "preceptor Germaniae"; d) Valentim Friedland (Trotzendorf) e a "república de escolares"; e) João Sturm e o ginásio de Estrasburgo; f) João Calvino e a Academia de Genebra.

C. Pedagogos católicos

a) O concílio de Trento: seu interesse pedagógico; b) Ordens religiosas dedicadas ao ensino; c) A Companhia de Jesus: os seus colégios; a Ratio studiorum.

O Colégio das Artes; a Universidade de Évora.

O séc. XVII

1. Francis Bacon e o Novum Organum; 2. Descartes e as "regras" do seu método; 3. Radtke a sua Didáctica Nova; 4. J. A. Comenius: a Didactica Magna, a Janua Linguarum, o Orbis Pictus; Francke: as suas realizações pedagógicas; 6. Jonh Locke: o conteúdo dos Some thoughts concerning education; a influência em Martinho de Mendonça; 7. Os Padres do Oratório; 8. Port-Royal; 9. Fénelon; 10. S. João Baptista de La Salle. 
O século XVIII

1. Rollin; 2. Rousseau: a psicologia de Rousseau; a pedagogia de Rousseau; a influência de Rousseau: filosófica e religiosa, política e social, literária; 3. Basedow; 4. A Revolução Francesa e Napoleão.

O século XVIII em Portugal: a) Martinho de Mendonça; Vernei; Ribeiro Sanches.

Alguns pedagogos contemporâneos

A. Na Alemanha: 1. Filósofos que influenciam a Pedagogia; 2. J. F. Herbart; 3. F. Fröebel; 4. Otto Willmann; 5. George Michael Kerschensteiner.

B. Na França: 1. Marc-Antoine Jullien de Paris; 2. Mgr. Dupanloup; 3. Alfred Binet; 4. Alain; 5. Henri Bauchet; 6. Roger Cousinet; 7. Célestin Freinet; 8. o Plano Langevin-Wallon.

C. Na Suíça: 1. H. Pestalozzi; 2. o Padre Girart; 3. Mme. Necker de Saussure; 4. Edouard Claparède; 5. Adolphe Ferrière, 6. Eugene Davaud; 7. Jean Piaget; 8. Louis Meylan.

D. Na Bélgica: Ovídio Decroly.

E. Na Inglaterra: 1. Herbert Spencer; 2. John Henry Newman; 3. Baden Powell; 4. o "Education Act" de 1944.

F. Na América: 1. W. James; 2. J. Dewey; 3. Helen Parkhurst; 4. Carleton Washburne; 5. Carl Rogers.

G. Na Itália: S. João Bosco; Maria Montessori.

Em 1972, Joaquim Ferreira Gomes apresentava, ao Conselho da Faculdade de Letras, um pedido de autorização para continuar os seus estudos de Pedagogia em Lovaina, no ano lectivo de 1972-1973, ao que o Conselho anuiu ${ }^{46}$.

Em sua substituição, as aulas da cadeira de História da Educação foram atribuídas a Aura Montenegro Ferrão, também ela docente do Grupo de Filosofia e dedicada aos estudos de Psicologia ${ }^{47}$. Não admira, por isso, que o seu programa fosse radicalmente diferente do de J. Ferreira Gomes.

A sua análise revela-nos uma temática toda ela centrada no séc. XVIII, com alguma extensão ao séc. XIX.

Em traços largos, poderemos apresentar assim o seu programa:

${ }^{46}$ Acta de 18 de Janeiro de 1972.

${ }^{47}$ Veja-se a sua bibliografia, nomeadamente a sua tese de doutoramento, apresentada à Universidade de São Paulo, Brasil, Dislexia - disortografia: investigação psipedagógica na escola primária. Coimbra, Instituto de Estudos Psicológicos e Pedagógicos, 1974, bem como a lição das suas provas de agregação, Psicologia escolar e medidas mentais (1979). Na acta do Conselho da Faculdade de Letras, de 27 de Novembro de 1972, há notícia de que a docente dera conhecimento do seu doutoramento, com êxito, na citada Universidade do Brasil. 
1. Rousseau: traços da sua época e da sua vida.

2. Evolução da sua doutrina: 1 . a crítica da vida social; 2 . a exaltação da natureza; 3. política e educação; 4 . a influência de Rousseau.

3. A Revolução Francesa e as suas reformas no campo da instrução: 1 . os cadernos de 1789; Mirabeau; a Assembleia Constituinte e Talleyrand; o projecto de Condorcet; a obra da Convenção: projecto Lanthernas, Romme e Lepelletier-Saint-Fargeau.

4. O iluminismo português no reinado de D. João V.

5. Clima político, social, intelectual e religioso da época pombalina como propedêutica à reforma da Universidade.

6. Os Estatutos pombalinos da Universidade de Coimbra.

7. Os grandes educadores contemporâneos: H. Pestalozzi; J.F. Herbart ou a educação pela instrução; F. Fröebel; o Padre Girat; J. H. Newman; Herbert Spencer; 8. João de Deus e os jardins-escola; a Cartilha maternal; 9. John Dewey; Helen Parkhurst; 10. Carl Washburne; 11. George Kerchensteiner; 12. Ovide Decroly; 13. Edouard Claparède; 14. Adolphe Ferrière; 15. Maria Montessori; 16. As Irmãs Agazzi; 17. Henri Bouchet.

8. A Educação permanente: Escolas de Pais.

No ano seguinte, Joaquim Ferreira Gomes retomava o serviço docente e a cadeira regressava ao seu programa.

\section{Conclusão}

Ao longo de quatro décadas, a cadeira de História da Educação da Secção Pedagógica da Faculdade de Letras da Universidade de Coimbra conheceu quatro $^{48}$ docentes: Joaquim de Carvalho, Sílvio Lima, Joaquim Ferreira Gomes, Aura Montenegro Ferrão. Contudo, apenas dois deles assumiram, de facto, a sua qualidade de docentes da cadeira, Joaquim de Carvalho e Joaquim Ferreira Gomes, uma vez que os restantes o foram circunstancialmente, em situação de recurso. Por isso, Joaquim de Carvalho e Joaquim Ferreira Gomes são os nomes marcantes da docência da cadeira. Pela sua proximidade no tempo e pelo facto de a sua docência ter correspondido a um tempo de claro alargamento no acesso quer ao ensino universitário, quer à profissão docente, o nome do segundo ainda

\footnotetext{
${ }^{48} \mathrm{Na}$ verdade, não consideramos José Ferreira da Silva, tão efémera e sem marca foi a sua passagem pela docência da cadeira. A mesma ausência se verifica em Joaquim Ferreira Gomes, O ensino da Psicologia e da Pedagogia nas Universidades portuguesas de 1911 a 1973. Separata de Revista Portuguesa de Pedagogia, vol. XXVIII, n. 3 (1994), p. 337-370.
} 
hoje é recordado por muitos e muitos professores ou ex-professores que fizeram a sua formação pedagógica em Coimbra ${ }^{49}$.

Os programas que os docentes apresentavam aos seus alunos têm a marca do tempo, mas também a das suas personalidades: Joaquim de Carvalho era um intelectual ligado à história das ideias, do pensamento, da cultura; Joaquim Ferreira Gomes era um homem ligado à teologia, à cultura eclesiástica, que buscou uma formação própria em História da Educação e uma actualização em Ciências Pedagógicas. Por isso o seu programa representa uma verdadeira actualização relativamente ao de Joaquim de Carvalho, quer em âmbito cronológico, quer, sobretudo, nas temáticas abordadas. De qualquer modo, ambos marcaram o seu tempo, na regência da cadeira de que foram responsáveis.

Quanto ao nosso trabalho, se ele serve para trazermos à luz alguns aspectos seguramente menos conhecidos do que foi a existência da cadeira de História da Educação, do Curso de Ciências Pedagógicas da Faculdade de Letras da Universidade de Coimbra, temos consciência de que se poderia espraiar por outros olhares, nomeadamente pela frequência da cadeira e pela origem dos seus alunos ${ }^{50}$. Reputando tais aspectos de um interesse muito assinalável, excluímo-los, por agora, dada a exigência de disponibilidade de tempo que essa investigação comporta.

Num conspecto mais alargado, esta nossa investigação traz à evidência, também, alguns aspectos do trabalho e da gestão dos saberes na Universidade. Ambos se orientam segundo as especializações e os centros de interesses dos docentes, os quais podem, ou não, coincidir com as necessidades de formação dos discentes, presentes em algumas circunstâncias, de que a formação pedagógica é exemplo.

Recebido em/Text submitted on: 16/03/2011

Aceite em/Approved on: 16/05/2011

${ }^{49}$ Para se ter uma ideia do número de alunos que terão passado pela cadeira, bem como pelas restantes da Secção Pedagógica, como é óbvio, cite-se a referência que se lhe encontra na acta da reunião do Conselho da Faculdade, de 15 de Abril de 1970: 750 alunos. O número é de múltiplas leituras, que não nos ocupam, no momento.

${ }^{50}$ Ainda foi iniciado o trabalho de levantamento e análise dos processos dos alunos candidatos à matrícula na cadeira, mas depressa se revelou inexequível para o âmbito de um simples artigo, tal o trabalho de que necessita. 